\title{
A Momentary Anesthesia of the Heart
}

\author{
Lauren Berlant
}

Published online: 27 December 2014

(C) Springer Science+Business Media New York 2014

It has not been simple to construct a response to these three essays. It is not just that each sees such a different mind that I might as well be three persons rather than one (I typed "free," so maybe it's a little self-estranging). It is that they each extend something from my work that was unpredicted by my own sense of what it might do. Criticality works this way, doesn't it? There's a greed to it. It's why people read badly. It is why they read passionately, with generative focus. It is why they can anchor themselves somewhere with a thought and then grasp a movement from there that makes more possible fresh propositions, orientations, disturbances, and clarifications.

I like that about criticality. When it works, a transference relation takes hold that allows both for the figuration of the familiar and the non-relation that is always there at the start of a genuinely original encounter. A comfort zone meets an alien one and a drama develops about what kinds of repetition and change can be borne. Then, there are all the exterior pressures interfering with focus that want us to hazard wild explanations and connections because we sense we see something but can't tell quite what it is.

I am grateful to all of the writers for the closeness and movement of their thought with and beyond my own. Recontextualization hits the authorial body and makes it pay attention to more things than are explicit in the work. It takes you out of yourself while forcing you to reoccupy your tendencies. (I'm kind of amused at the pronoun frenzy here, at first unintentionally performing what I'm describing, but now a record of it.)

Reading with Spinoza and Deleuze, Michael Hardt would see in this account of being affected an expansion of what constitutes the body itself, involving an enlargement of what a person can do. I'm not sure that absorbing multiplicities into the idiom of the expanding body is how I would have described the effect of being affected, but now his writing is in me and becomes, whether I like it or not (I do, but that's irrelevant), a part of how I respond.

By contrast, Robbie Duschinsky, Monica Greco, and Judith Solomon's paper begins with the form of two objects (two persons or a dyad and a world) distinguished by their exteriority to each other. In the object-relations/policy nexus they describe, the "multiplicity" of the relational subject is not as promiscuous as it is in the Spinozan tradition. Located in the liberal, ideological struggle over the family, their address to relationality begins with the tableau of attachment between competent and incompetent subjects, the mother and child in particular, whose very separateness-in-relation provides the occasion for state intervention and theoretical

L. Berlant $(\bowtie)$

Department of English Language and Literature, University of Chicago, 1115 East 58th Street, Chicago, IL 60637, USA

e-mail: 1-berlant@uchicago.edu 
speculation. Their essay attempts to disturb this model of individual responsibility as the primary organizing factor for the good life.

In contrast to both, Jackie Stacey focuses on the difference between "human relationality" and "an energy flow between multiple forms of life". In her work, non-sovereign relationality is not personal, between persons. She separates being-in-relation from affectual resonance, which plays across the surface and in the air of bodily action, rather than structuring individual or mutual interiority, as in our first two cases. Of course, the difference she registers between affect and relationality might emerge more starkly here because the other essays involve realism about how people live; in contrast, Stacey's scene is aesthetic, honed in on what an actor can do to create a persona reliable enough to shape-shift while being recognizable atmospherically. This requires appearing as an affective event from within a body anchored to star-identity's iconicity. But, in Tilda Swinton, Stacey might be offering us an image of any subject's potential to become a figure of movement who is, counter-intuitively, intelligible insofar as she is always performing withdrawal from a norm's magnetic field.

Affect theory provides an account of how the materiality of the world concretely shapes the atmospheres that persons move through and can imagine acting in; it is an account of visceral disturbance and presumes an irregular pattern of focalized attention and what's unreckoned in proximity to it. These days, I prefer the figure of metabolization to describe this situation, which I learned from Laplanche ([1992] 1999). To metabolize a thought or impact allows for its partial absorption, transformative redaction, and an energetics that induces meaning from an object and yet also allows for what's enigmatic about its location in mood and ambiance. It foregrounds the fact, or at least I think it's a fact, that both intimacy and alterity are constitutive features of the non-sovereign relation, which is defined by the mutually disturbing effects of proximity both on subjects and in the world. To think of affect as a metabolizing stimulus allows for the embodiment of affective impacts within relation without needing to oversolidify oneself, one's objects, and the field of consequences. In this way, figural and phantasmatic effects can be worked with even as apparently solid anchors are held onto, for dear life.

These essays metabolize in their own ways some concepts I have floated: their keywords are affect, attachment, and flatness. I love the idea that a work can float a concept, allowing the spirit of play to enter the fraught space of curiosity, scholarship, curation, synthesis, explanation, desperation, aggression, and desire that engaged criticality amounts to. Without play, nothing moves, as we know from losing teeth. When Bergson writes that laughter is "a momentary anesthesia of the heart," this is what he gestures toward (1911: 5). The sheer impact of a thing induces a suspension of self-encounter where breathing, noticing, and not knowing happen so that an alien concept or world can begin to be metabolized, to become different and intimate.

The multiple kinds of pull through which a concept draws together a scene for elaboration allow at once all sorts of openings and defenses, including and despite whatever an author's desire admits that it wants. One thing I see: in these critical works, concepts hold distinctions in proximity that might otherwise be flying away in different directions. That makes their concepts both strong, in the sense of "governing," and weak, in the sense of "linking." All of these essays are wondering about how that happens, whether the tensions require resolution, and how that might be accomplished. By "the tensions" I mean both what's in my work and also what's in the world's work of inefficient and overdetermined self-extension.

I begin with the most straightforward and go to the most intricate argument. Michael Hardt's extremely useful and beautifully elaborated essay, "The Power to Be Affected," uses

${ }^{1}$ I learned the difference between strong and weak thought from Eve Kosofsky Sedgwick, Touching Feeling (2003), p. 134. 
Spinoza and Deleuze as foils to or even sources for my recent work. Hardt is mainly engaged with Cruel Optimism. Here, the question is what it means to think about flourishing in relation to the good life and how one's capacity to be educated in affective response and selfdevelopment will induce these conditions positively or negatively. The intellectual conjuncture can be summarized as follows: my recent work claims that a social theory rooted in nonsovereign relationality has a better shot at describing the ways relations of power take shape than do social theories rooted in dramas of individuality or structure and agency. In this view, autonomy and sovereignty are styles of being within relationality rather than being foundational states violated or protected by power. It is not that I see non-sovereignty as superior to liberal models of autonomy and individuality; my proposal is that these latter figural separations are second-order styles to what is fundamentally in relation, only minimally controllable, and incapable of the heroic action from the outside that a lot of our fantasies of power would suggest.

Hardt sees this account of a relational realism extending from the tradition initiated by Spinoza and finding contemporary amplification in Deleuze. The presupposition he follows through (against Carl Schmitt) is that a problem for action arises when one presumes that there are no sovereign subjects - how do we imagine change to happen if the subject is passive, that is, primarily the convergence point of multiple forces that affect how he is to appear and move? Spinoza argues that the subject is more affected by the world than effective in it. If the power comes mainly from the outside, the subject then must not only "discover the means" to increase his power from within that relation but to increase it for good. To increase it for good, paradoxically, is not to inflate oneself as agent but to increase one's power to be affected.

In his beautiful discussion of "yel" "or," Hardt notes that the relation between being affected and being affecting is an ultimately equivalent scene of action for Spinoza and Deleuze and that the good of being open to being affected will redound in action that can follow out positive and negative paths. The anchoring word for this positive directionality is "joy." So, the first point is that to be open to being affected is to be open to the power of the world, to virtue, and to joy. The second is that we do not yet know, and never will, what the body can do because the work of becoming open to what's joyous and virtuous in the world is complex and ongoing. Hardt does not want to sentimentalize this situation, calling it a "briar patch" of difficulty. But he does believe, with Spinoza and Deleuze, that "once the cause is internal and the affection is active, then you are no longer subject to chance: the affect can be prolonged and repeated as long as it brings you joy."

I love this sentence. But what is "joy"? One thing that makes Hardt's essay difficult and the thought it remediates troubling in a good way is the aspiration toward the end of chance as though that end were possible, if indeed one is truly and constitutively open and committed to attending to being in relation. Maybe this is a simple problem: perhaps the end of chance lurks as a horizon but being in life remains a project of what Brennan calls "discernment," which here would be the capacity to judge what increases one's power to be affected by joy and to act from its teaching about the appetites and ethics (2004: 117-140). But formally, Hardt still wants it both ways, a little: the essay contains caveats but ends up bringing you the joy of joy.

The essay's contrastive analogies, accordingly, tend to point to dark aesthetics-Dante's Inferno and Conrad's Heart of Darkness. These scary, punitive works of moral guidance in an impossibly fallen world cast complexities themselves as threatening and miserable. In a longer piece or a conversation between us, I would want Hardt to go further into the heart of darkness to complexify or clarify ("yel") the relation between threat and desire and between sad and joyful passions, as they are not only antitheses pointing in opposite directions, like Orpheus and Eurydice. 
Hardt knows this. But in the essay, the energy to overcome what can't be overcome points away from what he knows. I want this tradition better to be able to deal with the difference between a joyous structure, say, and the surging, expansive feeling of vernacular joy. I want this tradition to describe the disturbance of joy in a way that complicates its distinction from the briar patch. Only moving within the complexity of relation can enhance our sensual cohabitation. The rhyme makes this sound easier than it is, I realize.

This leads us to the second, more difficult matter of concern: the relation of the vernacular to the conceptual or philosophical. A central problem in affect theory is the relation of ordinary emotional discourse to the philosophical deployment of concepts and the critical assessment of structure. Hardt's piece is short, I acknowledge, but one efficiency it embraces is the assertion that it is "less important" to figure the relation of the vernacular to the conceptual than it is to follow out how being affected can expand positively through joy. Let us not admit impediments. Yet, this very relation matters deeply to our understanding the phenomenology of collective life in the circuits of affectus.

Again, we know that Spinoza thinks that joy is not joy, but the power to act. So, when the essay closes with the promise of joyful relations, does that mean, merely and profoundly, the promise of activity? I do not think so. How does the affective in the active tap into the vernacular, and where else does it go? Barthes (1977) might call this scene an enactment of the relation of the obvious to the obtuse, the third, meaning: a scene of figuration that points beyond representation. In Barthes' work, obtuse meaning isn't a hoard or archive of all the failures or misuses in an invested term, but the empty space never to be filled by those uses. When the question is political, the noise in that space is one of the things we are experimenting with to provide infrastructures or structures (depending) for a rehabbed relational potential.

Thus, I am not just drawing a pedantic tableau. Nor am I merely repeating my meditation on joy in the previous paragraphs. At stake here is not, again, "how can we know?" but "what are we offering for action once we take sovereignty off the table?" We cannot develop this question if the vernacular is canned on behalf of the concept's arc of movement.

Hardt seems to recognize that few people read politically engaged theory these days without a reparative aspiration. As he narrates how the possibility of change shifts from the subject's radical passivity to one that "annexes" what's powerful in the world toward transformative action, he annexes the language of therapeusis. Hardt writes:

The advice, if Spinoza were your therapist, could be as simple as this: first, discover your body's power to be affected and the affects that compose it; and, then, if an encounter with someone or something results in joy, form a relationship with it, make it part of you, and transform the passive affection into an active one so that you can repeat the encounter or make it last until the joy no longer results. You have to recognize that you are not a fixed entity but a bundle of relations and your task is to compose new joyful relations and decompose sad ones.

If Spinoza were our therapist, we would have to ask him, what is the relation of my affect to my capacity to act? If the feeling of joy is not the same thing as the sense of it, how do I trust or not trust my feelings? How do I distinguish intelligence from delusion? Is this a kind of consequentialism, in which one is always tracking the data of an experimental life and hoping that one has developed, after all, a good sense of direction? Does it require faith that one's instincts for self-knowledge are developing proper discernment? What about the ease with which people confuse sovereign grandiosity with the power to act and the thrill of acting powerfully with joy? What about the case where my joy makes me conservative and averse to openness to be further affected? And how do I not become paralyzed, but live experimentally, within the field of these interruptive questions that are both defenses and openings? 
Additionally, as Flatley (2001) has described, it might be possible for people who equate depression with sadness and blockage also to see them as pointers to the otherwise of the messed up world. The sad passions can make us both more and less stuck. It is not just a matter of being fooled by them, but being multiple and also meaningless in our nonsovereignty. Sometimes affect theory needs psychoanalysis and sometimes it's the other way around. But both of them are arguments for being skeptical about what constitutes the transformative event.

Indeed, where knowing oneself and the world are concerned, and as the history of ideology demonstrates, the problem of mediating the viscera to oneself and to others is a most difficult one; the messy transregister existence of affect cannot be tamed even if one wants to delay dealing with the convergence of forces. It raises questions that are at once philosophical, political, and visceral: about the need for and ruses of self-skepticism, reason, the discipline into normativity, the relation between structural and affective vulnerability, and the specificity of people's lifeworlds. Because our forms of openness to each other may also be defenses against being affected, the vernacular assurance about what's joyful and sad demands its own interruption and mobilization.

In any case, the affective vernacular is not sloppiness in contrast to the concept's precision. Both point to norms of form and its disturbance that are at once clear and enigmatic. When I read Spinoza, I see that these matters concern him because he sees how deluded a person can be. At the same time, we have to conceive of action within the space also occupied by all of the noise that remains to be transfigured, not negated.

It is hard not to want joy to feel like joy or to have the affects feel like maps for action. Duschinsky, Greco, and Solomon face the same problem with the concept of attachment and the different kinds of projection onto it that organize social discourse and psychological research. Their essay addresses some other reasons why to pursue and not presume the relation among the vernacular, the phenomenological, the structural, and the conceptual kinds of beingwith: because historically the obscurity of these relations have affected the shape of biopolitical modes of subjection in formal, policy, and scientific domains.

In their essay, the questions are as follows: What is the relation between attachment and subordination? Is attachment a good, a synonym for subordination, or just a fact about the inevitability of non-sovereign relation? Is dependency itself a form of subordination that teaches us how to love our masters? What is the relation between intersubjective vulnerability and that which is seen to derive from social location, especially in terms of class and economic exposure? Is it possible to cast dependency as something other than subordination, to defeat once and for all the Lockean analogy and neoliberal moralism? What is the relation between a love of the state and of an intimate or between dependency on a state and on a caretaker? Is it possible ever to think social membership without subordination serving as the foundation? And how do we change the cluster of norms within the conventions of an analogy whose very powerful terms magnetize such different kinds of meaning and affect?

Their essay responds to this problem set by offering a better method. It hopes that "reconciliation and integration" of materialist fantasy, ideology, and policy with queer political theory and psychoanalytic models of attachment might counter conservative state maternalism and the kind of feminist counter-response that dismisses attachment as state patriarchal moralism and a constraint on social practice.

The essay also hopes to queer our understandings of sociability a bit, by seeing attachment not as a simple performance of trust and trustworthiness but a complex relation of affect to social belonging, normative aspiration, experimental life, performance, anxiety, and being reliable. Moving through work on attachment by Judith Butler and me, it suggests that resorting to 
attachment theory can alter how the pressure to be adequate to non-sovereign sociability appears. This is because the object of attachment theory is relational style itself.

I learned to think this way from reading with Melanie Klein, Christopher Bollas, and Adam Phillips, and also Leo Bersani. John Bowlby and Ainsworth came later, and much later still Steiner (1993, 2011), whose concept of the "psychic retreat" also describes the ways that behavior can be a defense against the exposure of tenderness while also providing an opening, a way into that tenderness, protecting attachment against the threat of attachment. This motley ensemble helps me grope toward understanding the patterning of relation without presuming a subjective and expressively coherent orientation toward it and without symptomatizing inconstant styles of orientation out of context as healthy or not.

Duschinsky, Greco, and Solomon's gambit is that, because it expands the field of relational style, queer theory can queer attachment theory, which already had its own intimacy-creative tendencies. Ainsworth's great contribution to attachment theory, after all, was to aestheticize it, to see that behavior mediates or figures an internal state without necessarily expressing in affective terms. The insight of Duschinsky, Greco, and Solomon's essay is that once one sees caretaker-child relations no longer as a thing but as a scene of figuration, that scene appears no longer as an expression of the natural goodness of normative form. One then understands behavioral patterning as an expression of the paradox of internal and external divisions and stressors that induce attempts at repair or at least management.

At this point, we are in proximity to what has come, in queer theory, to be called "negativity." As Lee Edelman and I have argued, negativity is not an extreme, exceptional shattering of the subject; nor is it some kind of subterranean truth that one's sociability is a fantasy of disavowal that covers over, like a comb-over hairdo, one's own aggressive will not to experience one's non-ideal subjectivity. ${ }^{2}$ Negativity is a scene of incompatible subjective forms to which we are attached. My preferred figuration is to see negativity as overdetermined - that is, a piling on of relation that is experienced as cleavage or negative drama only when one is dying to be sovereign. The neither/nor is actually a both/and. As we slowly peel away the sovereign from some image of the a priori individual, as we begin to see it as a fantasy that relieves the pressure of being in relational action, it can be replaced by a version of autonomy that we know always to be relative. Sovereignty is a shortcut and a blinder, a fantasy that we can achieve being absolute. The urgency of the affect is a map to its inevitable failure.

The ambition to effect this shift motivates my supplementation of "wait up!" to the Althusserian "hey you!" in "Two Girls, Fat and Thin." Duschinsky, Greco, and Solomon get at one part of this motive:

Attachment provides an important site at which, as Berlant explains, we not only receive subjugation as a particular kind of person ("hey you!") but also can address and change ("wait up!") our capacity to be affected with and by cultural forms and other people.

One is forced, in interpellation, to be affected whether one is open to it or not: this defines the encounter with organized power. At the same time, one is also actively engaged in what Hardt/Spinoza called "annexation," the willingness to become different within the force of relation.

But there is another thing. In the Gaitskill/Sedgwick essay, I am also thinking about the temporality of the subject's self-encounter, about the ways that attachment is a constant surprise, and not just a fact about us and our anchors. We may not be surprised to be attached to our caretakers - although even then, the Harry Harlow experiments opened the door for

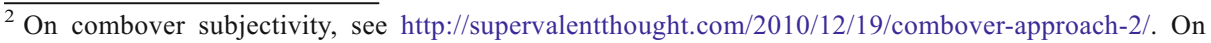
negativity, see Berlant and Edelman (2014) Sex, or the Unbearable.
} 
such a surprise when different relations available for care turned out to bring different resources to our attempts to thrive. ${ }^{3}$ But in moving through life, one is constantly belated to one's attachments. We are constantly discovering that we are in them. I have switched to the plural here because these surprises are as much about attachments to collective life as they are located in the singular relation. That part of interpellation, the unconscious part, is also what I meant by "wait up!"

Does that context change at all how we might develop Duschinsky, Greco, and Solomon's interest in shifting attachment from the image of the growth of the baby sovereign to the figure of a relational style that is held dynamically by all participants in an attachment, including the state and capital? Why does it matter that "the strange situation" reveals glitches in the representation of attachment in a kind of hieroglyphic style?

"The strange situation" reveals emblematically the impossibility of being able to presume that organized behavior copies an emotional infrastructure. But, the state still wants to have a policy encouraging some kinds of motherhood and some kinds of support for attachment. Like the law, the state feels that it has to presume continuity between behavior and emotional states. It also wants to redistribute responsibility, blame, and insecurity of social standing. What is to be done? Duschinsky, Greco, and Solomon's ambition is to produce a post-melodramatic political society that allows for a new realism about attachment, a realism based in an admission that inequality distresses attachment, and that attachment style does not express only the interpersonal context of the affective environment of relation.

The question is whether the state and general discourse can leave behind the register of universal sanctuary in intersubjective attachment for a more mobile understanding of relational security and whether it is possible to normativize a mode of relation that encompasses both what humans do to each other and the labile environments of adjustment in which that doing is invented, scavenged, and relied upon for continuity. When the political, economic, and everyday life conditions are not in place to sustain the work - because it is work - of relational attachment, there is less room for resilience. If there were less class inequality and more resources for and creativity around child rearing, these situations would clearly improve.

But, it is also worth being historical about it, to get the big picture of what kinds of toxic knots we face to undo. We are all the effects of causes, scenes for the reproduction of history: class and population fragility reproduces itself over time. This means not only that explicit and tacit atmospheres of suffering transmit themselves in the same spaces where we learn to love but that we all learn the intimacy from people who don't know how to have it, who received it insecurely from other people throwing action at the scene of attachment from somewhere within it.

The question is, then, how we interfere with the reproduction of that situation, in which, to return to Hardt's essay, the joy of love and being loved might allow for the briar patch of not knowing how to hold another's tenderness or take in their aggression without amplifying it. Thus, I love the sentence Duschinsky, Greco, and Solomon write about the caregiving system that "cannot be regarded as solely a personal property of the individualised caregiver but in turn is fully a social achievement, which can be clearly seen when it is not adequately resourced." The political struggle is to make a world in which we identify the right things as resources and forge better ways to be resources for each other.

Jackie Stacey's wonderful piece "Crossing Over with Tilda Swinton - the Mistress of 'Flat Affect" gets at the problem of resourcing attachment less in the register of being as such or

\footnotetext{
${ }^{3}$ On Harry Harlow, see most recently Blum (2002) and Harry F. Harlow's "The Nature of Love," first published in American Psychologist in 1958, now at Classics in the History of Psychology, http://psychclassics.yorku.ca/ Harlow/love.htm.
} 
policy and politics, and more in the affective register of aesthetics. It is an exemplary case study of how an iconic acting and embodiment style can magnetize an exciting tension among antithetical norms and wishes for the sentimental and the playful, the wildly and scientifically experimental. It also testifies to the failure of queer and feminist theory really to open gender up not just to sexuality but to affect — or let's just say that we are at an early stage still.

What is the beyond of the androgyne, the butch, the tomboy, the trans, and the genderqueer? What are these concepts reaching toward that cannot be captured by a phrase? How does a body in excess to the phrases that would imprison its potential appear, nonetheless, to be available for startling attachment? How does affective virtuosity find its scenes for an inventive elaboration, one that will pull people in while leaving them open for disruption? How do we ask historical questions about atmosphere in relation to diverse forces organizing themselves around a specific scene and set of bodily relations? This question set is central to assessing all affect, all attachment, and all living in relation. They organize how figuration operates in affect theory: as a magnetic proposition that resonates within representation, wrinkling it. Where Tilda Swinton is concerned, stark whiteness, stark thinness, starkly reduced and refined character, intense overhoned energy, and a pleasure in surface aesthetics move through the gendered conventions of imaginative failure to encompass the sublime and the cartoon. That last part is what allows Stacey to tell a story not just about Swinton as the petit objet á (femininity inside and outside of the Symbolic) but also about what kinds of energy become unbound when a feminine body plays implosively with all the available fantasies. "Implosive" is a way of talking about flatness without literalizing the flat to an inexistent affect or underwhelmed impact.

So, while Stacey's too is an essay on attachment, the attachment to the structure of feeling that is femininity, it does not rely on a normative notion of an anchoring object onto which overclarified fantasies are projected, identifications are fostered, or human empathy is transferred through the feminine benefit. Stacey is interested in the drama of this negative appearance, in Swinton's determination that her characters seem at one with their appetites. Swinton is a metafigure of a freedom to be a surface that is protective of its subjective membrane: she shows up as a figure of inwardness in relation. This, more than muteness, is what makes her "flat."

I might push Stacey's creative and searching attention a little further, too. I learn from this essay that Swinton, the mistress of flatness, its dominatrix and its illicit lover, plays with the norms that govern the destinies of femininity simply to be too much to govern. Stacey demonstrates that in Swinton, the surface of the actor's body and of the unsaid around it does not just oscillate between the sentimental and its others but loosens the object of femininity and enigmatizes the action of sexuality, virtually embodying post- 68 femininity-after-feminism as a kind of greedy something whose pleasures are critical and pointed toward freedom only if they remain unaccompanied by a theory or shame. That focus on singularity's push into experimentality might look to some to repeat some neoliberal tendencies to value what can't be extracted fully as value while nonetheless being transvalued. The virtuosity of being-inrelation without being constrained by reproductive norms induces the sense of flatness, negative capability, or non-sacrificial reduction into a governing appetite in which there seems to be no loss, even for the self-exploiter. All I can say is that we live when we live. But in addition, a mode of performative subtraction that intensifies the body beyond knowledge, biographical subjectivity, and mind-numbing play is the kind of teacher Hardt/Spinoza would call the professor of joy. Maybe this is why Swinton is not really uncanny. Because her mode is sublime reduction, an atmospheric effect that theoretically should not exist, because she represents the radical passivity of recessive action that seeks to be affected and to extend itself into atmosphere, her readers can move with her more than read her, dislocating their exposure 
to the bad passions and the impasse without end that allows for constant reenlistment in the ordinary tour of personality.

To close, each of these essays could be taught as a paradigm of explanation. All of them refuse to negate their organizing problem but give it texture and therefore open the question to being affected. One can have strong opinions without becoming a polemicist for them. For it takes non-sovereign, collective action to achieve a new object, and there is no moving from description to truth ahead of all the flailing laggers. Such a fantasy of performativity, when not backed by force of law, is a fantasy of a new normativity.

On the other side, we are exposed to the contingencies of an attachment to openness in a space of generosity for what does not quite fit, provide clarity, achieve repair. On the other side, it takes a willingness to collect a new cluster of potential associations for a question beyond what is convenient to one's own and the world's conventionality. It requires a capacity to desire what is incomplete in one's own thought and to discover critical satisfaction notwithstanding the gap between the grandness of our problems and the gestures we make to shift them. The mobilization of the impasse changes the object inducing it, too. This response aspires to be adequate to the force of my interlocutors' examples.

\section{References}

Barthes, R. (1977). The third meaning. edition: (1977). Image-Music-Text (trans. Heath S.). New York: Hill and Wang, 52-68.

Bergson, H. (1911). Laughter: an essay on the meaning of the comic. New York: MacMillan.

Berlant, L., \& Edelman, L. (2014). Sex, or the unbearable. Durham: Duke UP.

Blum, D. (2002). Love at Goon Park: Harry Harlow and the science of affection. New York: Basic Books.

Brennan, T. (2004). The transmission of affect. Ithaca: Cornell UP.

Flatley, J. (2001). Moscow and melancholy. Social Text, 19(1), 75-102.

Harlow, H. F. (1958). The nature of love. American Psychologist, 13, 673-685.

Laplanche, J. ([1992] 1999). Essays on otherness. In J. Fletcher (Ed.). London: Routledge.

Sedgwick, E. K. (2003). Touching feeling. Durham: Duke UP.

Steiner, J. (1993) Psychic retreats: pathological organizations in psychotic, neurotic and borderline patients. intro. R. Schaefer, New York: Routledge.

Steiner, J. (2011). On seeing and being seen: on emerging from a psychic retreat. New York: Routledge. 